\title{
Apresentação - Estudos sobre implementação de políticas públicas e suas relações com a (re)produção de desigualdades educacionais: um campo em construção
}

\section{Presentation - Studies about the implementation of public policies and their association with the (re)production of educational inequalities: a field under construction}

\author{
Naira Muylaert*
}

\begin{abstract}
RESUMO
A elaboração do dossiê Implementação de políticas públicas para o combate às desigualdades educacionais é composto por oito artigos que abordam questões sobre as várias fases do ciclo de políticas, desvelando seus diversos e complexos elementos, dentre eles as disputas políticas da agenda, os instrumentos de regulação, os recursos empreendidos, a atuação dos agentes implementadores e os possíveis efeitos sobre a garantia do direito à educação com vistas à diminuição das desigualdades sociais. Os objetos de estudo abordados nos trabalhos englobam contextos internacionais, nacionais e locais, e são analisados à luz de diferentes referenciais teóricos e abordagens metodológicas. O dossiê também é uma iniciativa que busca aproximações interdisciplinares, ao visar articular o campo da política educacional, ao campo da ciência política e ao campo da sociologia da educação. Dessa forma, acredita-se que o dossiê traz relevantes contribuições
\end{abstract}

* Pontifícia Universidade Católica do Rio de Janeiro. Programa de Pós-Graduação em Educação. Rio de Janeiro, Rio de Janeiro, Brasil. E-mail: naira@puc-rio.br - https://orcid.org/00000001-5161-0501 
que fazem avançar a produção de conhecimento acerca das políticas públicas educacionais e suas relações com as desigualdades sociais.

Palavras-chave: Implementação de políticas educacionais. Desigualdades educacionais. Ciclo de políticas públicas. Educação.

\begin{abstract}
The dossier titled Implementation of public policies to combat educational inequalities comprises eight articles focused on addressing issues concerning different policy cycle stages by disclosing their numerous and complex elements - such as policy disputes for the agenda, regulatory instruments, undertaken resources, implementing agents' performance and likely effects of these policies on the guarantee of the right to education - to help reducing social inequalities. The objects of study addressed in the dossier's articles comprised international, national and local contexts. They were analyzed based on different theoretical references and methodological approaches. The dossier is also an initiative to enable interdisciplinary associations by linking the Educational Policy field to fields such as Political Science and Sociology of Education. Thus, the dossier is expected to make relevant contributions to increase the production of knowledge about public policies on education and their association with social inequalities.
\end{abstract}

Keywords: Implementation of education policies. Educational inequalities. Cycle of public policies. Education.

Este texto tem como finalidade fazer uma breve apresentação dos artigos que compõem o dossiê Implementação de políticas públicas para o combate às desigualdades educacionais. A organização do dossiê, bem como as breves considerações aqui apresentadas, contou com a imprescindível contribuição da professora Dra. Ana Cristina Prado de Oliveira da Universidade Federal do Rio de Janeiro (UNIRIO) que, como colaboradora do dossiê e parceira de pesquisa, fez um trabalho de inestimável valor e a quem registro minha enorme gratidão.

Este dossiê é uma iniciativa que busca fomentar discussões teóricas e metodológicas sobre a fase da implementação de políticas públicas educacionais e sua relação com as desigualdades sociais. Se por um lado o tema das desigualdades sociais e educacionais é escopo de inúmeros estudos, o tema da implementação não é.

De um modo geral, a produção acadêmica do campo da Ciência Política analisa a política a partir de quatro fases centrais: agenda, formulação, implementação e avaliação, que são entendidas como processos contínuos, 
dinâmicos e muitas vezes sobrepostos. No campo da Política Educacional ganha força o modelo teórico metodológico do ciclo de políticas (BALL; BOWE, 1992; MAINARDES, 2006), formado por três contextos: influência, produção de texto e prática, que, embora sejam inter-relacionados, não são, necessariamente, temporal ou sequencial, e por isso se caracterizam como um ciclo.

A maioria dos estudos, em contextos internacionais e nacionais, prioriza o cenário da produção do texto e a análise nas fases de agenda, formulação e avaliação, relegando à fase da implementação uma importância secundária, havendo uma "grande lacuna nos estudos empíricos sobre a fase de implementação de políticas e os diversos elementos e fatores que a influenciam" (LOTTA, 2015, p. 16).

Essa lacuna é percebida nas diversas áreas de conhecimento, e na Educação não se faz menor. Em recente levantamento, Oliveira (2019) aponta a escassa presença (apenas 6,1\%) de artigos sobre implementação de políticas educacionais em periódicos nacionais e internacionais. O que se observa, de um modo geral, é que o campo da Educação se vale, prioritariamente, da literatura sobre o ciclo de políticas elaborada por Stephen Ball e colegas, mencionada acima, para analisar as políticas públicas educacionais. Ainda que a proposição analítica do autor destaque a dinâmica cíclica entre os contextos, os estudos que se valem desse referencial, ao abordar o contexto da prática, distanciam-se das discussões sobre as características da implementação. Nesse campo, raros são os estudos que se apropriam dos referenciais teóricos advindos da Ciência Política, que costumam focalizar mais a fase da implementação. No entanto, vale destacar, mesmo no campo da Ciência Política, objetos de estudo de outras áreas como Saúde, Assistência Social e Meio Ambiente, são mais abordados nas pesquisas, o que faz perdurar a lacuna de estudos sobre a fase da implementação de políticas públicas educacionais.

É com o propósito de sanar essa lacuna teórica e empírica que se constituiu a Rede de Estudos em Implementação de Políticas Públicas Educacionais (REIPPE $)^{1}$, com integrantes de diversas instituições brasileiras. Essa Rede vem, desde 2014, se debruçando sobre o aporte teórico e metodológico do campo da Ciência Política para a realização de estudos que focalizam a fase da implementação de políticas educacionais. Em particular, muitos desses estudos têm interesse em compreender como a implementação das políticas educacionais pode incidir na ampliação ou mitigação das desigualdades.

Esse propósito também embasa a elaboração deste dossiê temático, cujo objetivo é fomentar discussões em torno da relação entre implementação de políticas e combate às desigualdades educacionais, e promover aproximações interdisciplinares ao visar articular o campo da política educacional, ao campo da ciência política e ao campo da sociologia da educação. 
Com objetivos tão ambiciosos, o dossiê enfrentou algumas dificuldades para reunir estudos que focalizassem a fase da implementação - que, como já mencionado, não se fazem tão presentes no campo - e sua relação com a desigualdade, o que fez com que as outras fases do ciclo de políticas também fossem abordadas nos estudos que integram o dossiê. Por um lado, isso reforça a escassez de estudos sobre a fase de implementação e evidencia a necessidade de se empreender esforços para fomentar pesquisas sobre a temática. Por outro, enriquece o dossiê na medida em que os textos trazem interconexão entre as fases do ciclo de políticas, pois sua composição conta com estudos que abordam, além da implementação, as fases da agenda, da formulação e da avaliação de políticas. Essa interconexão reforça a relevância de não analisar a dinâmica da política desconsiderando suas outras fases. Com efeito, a implementação tanto depende quanto define as outras fases do ciclo. Assim, é considerando este lugar central da implementação e essa interconexão, que olhamos para as outras fases do ciclo de políticas abordadas por alguns dos artigos apresentados a seguir.

Inserido no tema da democratização do acesso à educação básica, o estudo de António António, Geovana Mendonca Lunardi Mendes e Osvaldo Hernández González, intitulado Políticas de Educação Especial numa perspectiva inclusiva em Angola: contexto, avanços e necessidades emergentes (1979-2017), aborda tanto a fase da agenda quanto da formulação. Embora não utilize como lente analítica o ciclo de políticas de Stephen Ball e colegas, e nem os referencias teóricos que discutem implementação, o estudo aborda a forma como Angola se apropriou da agenda política debatida pelos organismos internacionais sobre a educação especial e inclusiva para a formulação de políticas educacionais naquele país. A partir da Declaração dos Direitos Humanos de 1948, da Convenção dos Direitos da Criança ocorrida em 1989 e da Declaração de Salamanca de 1994, Angola vem formulando políticas públicas visando a ampliação da inclusão de crianças com necessidades especiais nas escolas. Nesse sentido, o estudo focaliza as fases da agenda e da formulação de políticas educacionais na perspectiva da inclusão.

Outro estudo alinhado à ideia de democratização - que, neste caso, é do acesso ao ensino superior - é o trabalho de Francilene de Aguiar Parente e Irlanda do Socorro de Oliveira Miléo denominado O Curso de Etnodesenvolvimento e a formação diferenciada e intercultural: contribuições no contexto educacional, sociopolítico e cultural da Amazônia. O texto trata da implementação do curso de licenciatura e bacharelado em Etnodesenvolvimento na Universidade Federal do Pará (campus de Altamira), que vem contribuindo para a formação acadêmica e profissional de populações tradicionais do contexto da Amazônia. O curso, formulado e implementado a partir das concepções inerentes às ações afirmativas, não é encontrado em outras instituições de ensino superior e 
possui características específicas que visam atender a um público determinado, contribuindo assim para a ampliação das possibilidades de atuação, barganha e negociação política desses atores sociais tanto na universidade, quanto fora dela. $\mathrm{O}$ estudo trata da implementação de um curso criado a partir do conjunto de ações afirmativas promovidas pela instituição e como essa iniciativa pode contribuir para a ampliação e interiorização do acesso ao ensino superior.

Menos alinhado à temática da democratização do acesso e mais afinado com o tema do reconhecimento étnico-racial, o estudo Socialização étnico-racial e racismo: dos saberes afro-brasileiros e africanos à construção da identidade étnico-racial de Patrícia Modesto Matos e Dalila Xavier de França objetiva analisar a percepção de alunos sobre a constituição de identidades étnico-raciais, a partir das experiências de socialização étnico-racial. Entende-se, no estudo, que uma das formas de socialização étnico-racial se dá por meio da aquisição de conhecimentos sobre a história e cultura de um povo, como garantida pela Lei 10.639/2003 (BRASIL, 2003), que alterou a LDB/96 (BRASIL, 1996) ao estabelecer como obrigatória a inclusão nos currículos escolares do tema História e Cultura Afro-Brasileira. A partir da percepção dos estudantes sobre a formação das identidades étnico-raciais, um dos achados da pesquisa é que a lei é implementada nas escolas. No entanto, aprofundar os processos de implementação da lei ainda é um ponto a ser desvelado por investigações futuras.

O trabalho de Wagner Silveira Rezende, intitulado Avaliação da alfabetização no Espirito Santo: uma análise do Paebes Alfa entre 2009 e 2017, focaliza a fase da avaliação do ciclo de políticas, ao se debruçar sobre a análise e descrição do programa de avaliação da alfabetização do estado do Espírito Santo, denominado Paebes Alfa. Embora focalize a fase da avaliação, o estudo inova ao dar ênfase à descrição das características do programa e não aos resultados de aprendizagem, aproximando-se assim da fase da implementação, pois descreve e analisa os vários elementos do Paebes Alfa, apontando seus limites e suas potencialidades.

Dos estudos que compõem o dossiê, quatro focalizam especificamente a fase da implementação de políticas, sendo que três deles fazem análises a partir da perspectiva bottom up, ao tratarem sobre a discricionariedade da atuação dos agentes implementadores, e o quarto utiliza o modelo analítico de síntese proposto por Richard Matland para abordar o tipo de implementação que caracteriza a Base Nacional Comum Curricular (BNCC).

De forma breve, importa aprofundar os conceitos mobilizados por esses quatro trabalhos para melhor compreender a relevância dos estudos sobre a fase de implementação de políticas. 
De acordo com Lotta (2015), a fase da implementação é definida como o momento em que a política é colocada em prática, ou seja, quando ela deixa de ser documento e passa a ser concretizada por meio da ação dos agentes implementadores. Há duas abordagens principais que analisam a maneira como a implementação da política se dá. A primeira é conhecida como top down e se caracteriza como um processo hierárquico e verticalizado, onde as decisões vem de cima para baixo. Ou seja, as políticas são formuladas por agentes do alto escalão e implementadas por agentes das burocracias de médio escalão e de nível de rua. Nesse sentido, há uma separação entre administradores (aqueles que executam as ações) e políticos (aqueles que decidem as ações), havendo subordinação dos agentes implementadores em relação aos agentes formuladores (WEBER, 1947). Na segunda abordagem, denominada bottom up, a política não é fragmentada; ao contrário, é compreendia como um continuum, onde a formulação da política é interpretada e modificada na ação do implementador. $\mathrm{O}$ enfoque analítico passa a ser os processos executados e não os resultados alcançados. No bojo dessa perspectiva analítica, estão os estudos que lançam luz para o exercício da discricionariedade dos agentes implementadores - em especial, aqueles definidos por Lipsky (2010) como street-level bureaucracy, ou burocratas de nível de rua, que são os agentes públicos do Estado que trabalham em contato direto com o público atendido pela política. Ou seja, são aqueles que efetivamente entregam o serviço da política ao cidadão.

Estudos que possuem este escopo analítico debruçam-se sobre a atuação dos burocratas. Essa atuação é entendida a partir das práticas e das interações que eles estabelecem na realização do trabalho que executam. Essas práticas e interações são fundamentadas nas regras e normas da política elaboradas na fase da formulação e, também, nas crenças e valores individuais dos burocratas (LOTTA, 2015), o que faz com que cada um tenha atuações diferenciadas na entrega do serviço. Embora existam regras e normas previstas na formulação da política que conformam a atuação dos burocratas, eles mobilizam suas próprias crenças e valores que conferem a eles certa autonomia para tomar decisões nos processos de implementação. Esta autonomia regulada pelas normas da política é denominada pela literatura como "exercício da discricionariedade", e é nesse sentido que os agentes implementadores são entendidos não apenas como executores de políticas, mas também como fazedores de políticas.

Embora a atuação dos burocratas de nível de rua já tenha sido bastante explorada em diversas políticas públicas de outras áreas, como a Saúde e a Assistência Social, poucos estudos dedicaram-se a investigar a atuação desses burocratas na implementação de políticas educacionais. Mais escasso ainda são os estudos que focalizam o olhar para a atuação dos burocratas de médio escalão - aqueles que conectam a fase da formulação e da implementação ao 
fazerem o elo entre os agentes do alto escalão e os de nível de rua, por meio da tradução de decisões em ações (CAVALCANTE; LOTTA, 2015). São eles os responsáveis por fazer com que as políticas elaboradas pelo alto escalão sejam colocadas em prática pelos burocratas de nível de rua. A principal função do burocrata de médio escalão é, portanto, coordenar agentes de nível de rua com $o$ intuito de operacionalizar a política formulada.

No dossiê há três estudos que focalizam a atuação dos agentes implementadores. Um deles - O Prêmio Escola Nota Dez (PENDez) - um instrumento de combate às desigualdades educacionais da alfabetização infantil, de Maria Océlia Mota e Diego Mota - direciona o olhar tanto para agentes do médio escalão quanto para agentes de nível de rua. Ao investigar a política de bonificação do estado do Ceará - o Prêmio Escola Nota Dez -, o estudo lança luz sobre como oito agentes implementadores de médio escalão e de nível de rua se apropriam e transformam o PENDez, compreendido como um instrumento de regulação do Programa Aprendizagem na Idade Certa (Paic). Um dos resultados evidencia que o PENDez, mesmo sendo uma política de bonificação baseada em princípios meritocráticos, também incorpora em seu desenho elementos de equidade, contribuindo assim para o combate às desigualdades de aprendizagem.

Os outros dois estudos alinhados à essa temática focalizam a atuação de diretores escolares que podem ser entendidos como burocrata de nível de rua ou de médio escalão. Não há um consenso na literatura sobre qual nível da burocracia o diretor se situa. Conceitualmente, Oliveira e Abrucio (2018) definem o diretor de escola como um burocrata de médio escalão em função do conjunto de tarefas que executa no seu trabalho. Os autores apontam quais são as principais tarefas e demonstram que elas são, em sua maioria, típicas do nível intermediário da burocracia, embora existam algumas que se aproximam do alto escalão e outras que se aproximam do nível de rua, havendo um certo hibridismo na função dos diretores. Em que pese esse hibridismo, Oliveira e Abrucio (2018) definem os diretores escolares como burocratas de médio escalão. Mesmo concordando conceitualmente com a definição feita pelos autores, Muylaert (2019) chama a atenção para a necessidade de se definir o escopo do serviço prestado pela política para se definir, empiricamente, se o diretor é um agente de médio escalão ou de nível de rua. Isso porque o hibridismo de suas tarefas pode deslocar o diretor de escola para um ou outro tipo de burocrata a depender da política que se analisa.

Com foco na discricionariedade da atuação dos diretores escolares, o estudo Seleção de diretores e o sentido da gestão escolar: percepções de diretores sobre o plano de gestão, de Maria de Fatima Magalhães de Lima, focaliza a política de seleção de diretores escolares do município do Rio de Janeiro. O escopo da pesquisa se volta para a investigação da percepção dos diretores sobre a 
implementação da diagnose e autoavaliação - elementos constituintes do plano de gestão, que se caracteriza como um instrumento para induzir a gestão escolar a utilizar indicadores educacionais, bem como definir metas e traçar estratégias para alcançá-las. Esse instrumento também é utilizado para aferir a competência técnica dos candidatos que concorrem ao cargo de direção de escolas.

Também com foco na atuação do diretor escolar, o estudo de Tereza Cristina de Almeida Guimarães e Elisangela da Silva Bernado, intitulado Questão de mérito: o acesso às vagas remanescentes em uma escola pública municipal Gonçalense , também tem como foco analítico o exercício da discricionariedade desse agente implementador. Por meio de um estudo de caso, o trabalho aponta que a atuação discricionária do gestor escolar pode incidir na reprodução de desigualdades educacionais na medida em que o diretor da escola investigada não atende ao disposto na Portaria Semed n. ${ }^{\circ}$ 96/2018 (SÃO GONÇALO, 2018), que estabelece normas para a matrícula em escola pública da rede municipal de São Gonçalo/RJ. Com isso, a escola não preenche o total de vagas estabelecido na Portaria, se afastando, portanto, do ideário da democratização do acesso à Educação Básica.

Outro enfoque analítico é abordado no estudo Contribuições dos estudos de implementação para a análise de políticas educacionais: uma breve discussão do contexto de implementação da BNCC, de Marina Meira e Alicia Bonamino, que utiliza o modelo sintético elaborado por Richard Matland para compreender o tipo de implementação das políticas curriculares nacionais, em especial a BNCC.

Os modelos analíticos de síntese se caracterizam como uma terceira geração de estudos que buscam transcender a discussão top down x bottom up, ao combinar elementos das duas abordagens com o objetivo de criar modelos explicativos sobre a fase da implementação, onde uma ou outra perspectiva de análise seja mais adequada. Os modelos de síntese, ao superar essa dicotomia, avançam em relação às duas abordagens tradicionais e trazem em seu bojo outros elementos, como governança, capacidades estatais, entre outros. Richard Matland é um dos autores que se alinha a esta terceira geração de estudos sobre implementação, ao propor um modelo analítico alternativo que sintetiza as abordagens top down e bottom up, por meio da combinação de conceitos importantes para a implementação de políticas públicas: ambiguidade e conflito.

A ambiguidade se refere ao grau de incerteza com relação aos meios e aos fins da política. Em muitos casos os implementadores conhecem os objetivos da política, mas não têm clareza sobre o que fazer para alcançar esses objetivos. Neste caso, a ambiguidade se dá em relação aos meios/processos da implementação. Em outros casos, a ambiguidade se dá em relação aos fins, onde os implementadores não sabem quais são os objetivos da política. Já o conceito de conflito diz respeito ao grau de aderência em que os agentes implementadores 
têm em relação aos objetivos e aos processos. Ou seja, o conflito tem a ver com o grau de concordância que os implementadores têm sobre o que deve ser feito e como deve ser feito.

Ao combinar os níveis de ambiguidade e de conflito de uma política, Matland (1995) elaborou quatro tipos de implementação: simbólica, administrativa, experimental e política. A definição dessa tipologia é apresentada no estudo de Marina Oliveira e Alicia Bonamino, que aponta os avanços e os limites dessa tipologia em relação às abordagens tradicionais. Complementarmente, as autoras operam os dois conceitos - conflito e ambiguidade - para a análise das políticas curriculares nacionais, onde concluem, preliminarmente, que a política em vigência - a BNCC - se enquadra numa implementação do tipo política.

Esta breve apresentação dos textos revela que o dossiê adquiriu um caráter abrangente e diverso, não apenas por contemplar as quatro fases do ciclo de política, mas por abordar diversas políticas que envolvem diversos segmentos e modalidades, como a educação especial e inclusiva, o ensino superior, o ensino fundamental e a alfabetização, implementadas em diferentes contextos. Dentre as políticas investigadas nos trabalhos estão:

- Política internacional: políticas de educação especial e de inclusão em Angola;

- Políticas nacionais: Lei de cotas, Lei 10.639/2003, que estabelece a inclusão nos currículos escolares do tema História e Cultura Afro-Brasileira e BNCC;

- Políticas estaduais: Paic/Prêmio Escola Nota Dez (estado do Ceará), Programa de Avaliação da Alfabetização (estado do Espírito Santo);

- Políticas municipais: política de preenchimento de vagas (município de São Gonçalo/RJ) e plano de gestão para a seleção de diretor escolar (município do Rio de Janeiro/RJ).

Essa diversificação também é percebida pelo uso de abordagens metodológicas qualitativas e quantitativas. De maneira descritiva, dados estatísticos se fazem presente na maioria dos estudos, sendo que a abordagem quantitativa é mais desenvolvida e aprofundada no trabalho de Patrícia Modesto Matos e Dalila Xavier de França, que realizaram testes de hipóteses e análise de variância (ANOVA).

Nesse sentido, com perspectivas teóricas e metodológicas diferenciadas, os textos que compõem o dossiê tratam de questões de extrema relevância para que se aprofunde o conhecimento acerca das fases do ciclo de políticas públicas, em especial a fase da implementação. Também contribuem para o campo educacional na medida em que evidenciam os vários movimentos que estão sendo feitos em vários contextos, instâncias e esferas que fazem avançar a compreensão das políticas públicas bem como seus efeitos sobre o combate às desigualdades e sobre a democratização do acesso à uma educação com qualidade. 


\section{REFERÊNCIAS}

BALL, Stephen; BOWE, Richard. Subject departments and the "implementation" of national curriculum policy: an overview of the issues. Journal of Curriculum Studies, London, v. 24, n. 2, p. 97-115, 1992. Disponível em: https://doi.org/10.1080/0022027920240201. Acesso em: 20 out. 2021.

BRASIL. Presidência da República. Lei $n^{\circ}$. 10.639, de 9 de janeiro de 2003. Altera a Lei $\mathrm{n}^{\circ}$ 9.394, de 20 de dezembro de 1996, que estabelece [...], e dá outras providências. Brasília, DF: Presidência da República, 2003. Disponível em: http://www.planalto.gov. br/ccivil_03/leis/2003/110.639.htm. Acesso em: 21 out. 2021.

BRASIL. Presidência da República. Lei nº 9.394 de 20 de dezembro de 1996. Estabelece as diretrizes e bases da educação nacional. Brasília, DF: Presidência da República, 1996. Disponível em: http://www.planalto.gov.br/ccivil_03/leis/19394.htm. Acesso em: 10 out. 2021.

CAVALCANTE, Pedro; LOTTA, Gabriela (org.). Burocracia de médio escalão: perfil, trajetória e atuação. Brasília, DF: INEP, 2015.

LIPSKY, Michael. Street-level bureaucracy: dilemmas of the individual in public service. New York: Russell Sage Foundation, 2010.

LOTTA, Gabriela. Burocracia e Implementação de Políticas de Saúde: os agentes comunitários na Estratégia Saúde da Família. Rio de Janeiro: Editora Fiocruz, 2015.

MAINARDES, Jefferson. Abordagem do ciclo de políticas: uma contribuição para a análise de políticas educacionais. Educação e Sociedade, Campinas, v. 27, n. 94, p. 47- 69, 2006. Disponível em: https://doi.org/10.1590/S0101-73302006000100003. Acesso em: 20 out. 2021.

MATLAND, Richard. Synthesizing the Implementation Literature: The AmbiguityConflict Model of Policy Implementation. Journal of Public Administration Research and Theory, [S. l.], v. 5, n. 2, p. 145-174, 1995. Disponível em: https://www.jstor.org/ stable/1181674. Acesso em: 20 out. 2021.

MUYLAERT, Naira. Diretores escolares: burocratas de nível de rua ou médio escalão? Revista Contemporânea de Educação, Rio de Janeiro, v. 14, n. 31, p. 84-103, 2019. Disponível em: https://revistas.ufrj.br/index.php/rce/article/view/25954. Acesso em: 20 out. 2021.

OLIVEIRA, Ana Cristina Prado. Implementação das políticas educacionais: tendências das pesquisas publicadas (2007-2017). Revista de Estudios Teóricos y Epistemológicos en Política Educativa, [S. l.], v. 4, p. 1-16, 2019. Disponível em: https://doi.org/10.5212/ retepe.v.4.009. Acesso em: 20 out. 2021. 
OLIVEIRA, Vanessa; ABRUCIO, Fernando Luiz. Burocracia de médio escalão e diretores de escola: um novo olhar sobre o conceito. In: PIRES, Roberto; LOTTA, Gabriela; OLIVEIRA, Vanessa (org.). Burocracia e políticas públicas no Brasil: interseções analíticas. Brasília, DF: INEP, 2018. p. 207-225.

REIPPE. Rede de Estudos sobre Implementação de Políticas Públicas Educacionais, 2020. Disponível em: https://www.reippe.com/. Acesso em: 8 nov. 2021.

SÃO GONÇALO. Portaria Semed n. ${ }^{\circ}$ 96/2018. Estabelece Normas Pertinentes à Matrícula para o Ingresso e Permanência nas Unidades de Ensino da Rede Pública Municipal de São Gonçalo para o ano letivo de 2019 e dá outras providências. Diário Oficial: seção 5, São Gonçalo, ano 2018, n. 1, p. 17, 3 dez. 2018.

WEBER, Max. The theory of social and economic organization. New York: Free, 1947.

Texto recebido em 01/09/2021.

Texto aprovado em 20/10/2021. 